\title{
Long-Term Safety and Effectiveness of Style 410 Highly Cohesive Silicone Breast Implants
}

\author{
Per Hedén · Giorgio Bronz · Jens Jorgen Elberg • Rika Deraemaecker · \\ Diane K. Murphy · Araceli Slicton · R. James Brenner · \\ Catarina Svarvar $\cdot$ Joost van Tetering $\cdot$ Leo Peter van der Weij
}

Received: 11 December 2008/ Accepted: 6 April 2009/Published online: 13 May 2009

(C) The Author(s) 2009. This article is published with open access at Springerlink.com

\begin{abstract}
Background In 2006, a single-center Swedish study demonstrated a low rupture rate and high patient satisfaction with the Style 410 shaped, form-stable gel implant. The current study aimed to validate the accuracy of the previously published results across multiple European sites.

Methods A total of 163 subjects ( $\sim 70 \%$ had augmentation $[n=112], 15 \%$ had reconstruction $[n=25]$, and $15 \%$ had revision $[n=26]$ ) underwent a physical examination followed by breast magnetic resonance imaging (MRI) for rupture detection. These subjects had been implanted for 5 to 11 years with at least one Style 410 shaped gel breast implant before examination. The secondary end points included lactation, reproductive and breast disease history
\end{abstract}

Presented as a poster at the 19th Congress of the International Society of Aesthetic Plastic Surgery, Melbourne, Australia, 10-13 February 2008 .

\section{P. Hedén $(\bowtie)$}

Akademikliniken, Stockholm, Sweden

e-mail: per.heden@ak.se

\section{G. Bronz}

Bronz Clinic, Lugano, Switzerland

J. J. Elberg

Rigshospitalet, Copenhagen, Denmark

R. Deraemaecker

Bordet Institut, Tumor Centre of the Free University of Brussels,

CHU St. Pierre, University of the Brussels, Brussels, Belgium

D. K. Murphy · A. Slicton

Allergan, Santa Barbara, CA, USA before and after implantation, and quality-of-life measurements and complications after implantation.

Results The implant rupture rate was $1.7 \%$ a median of 8 years after implantation. Capsular contracture was the most common complication noted at the physical examination, occurring for $5.3 \%$ of implants, and there were no cases of grade 4 capsular contracture. The postimplantation rates for lactation and reproductive problems and breast disease were lower than the preimplantation rates. Breast implantation surgery was considered advantageous by $91 \%$ of the subjects, demonstrating high patient satisfaction. Conclusions The Style 410 anatomically shaped, formstable gel breast implants demonstrated long-term safety and effectiveness.

Keywords Quality of life - Rupture - Safety · Silicone breast implants

\author{
R. J. Brenner \\ Bay Imaging Consultants, San Francisco, CA, USA \\ C. Svarvar \\ Department of Plastic Surgery, Helsinki University Central \\ Hospital, Helsinki, Finland \\ J. van Tetering \\ Kennemer Gasthuis Hospital, Haarlem, The Netherlands \\ L. P. van der Weij \\ Kliniek Klein Rosendael, Rozendaal, The Netherlands
}


The long-term safety and effectiveness of Style 410 shaped gel breast implants (Allergan, Santa Barbara, CA, USA) were previously studied by Hedén et al. [1] at Akademikliniken Hospital in Sweden. This was the first trial to use magnetic resonance imaging (MRI) rupture detection for Style 410 implants 5 or more years after implantation. Notably, the findings showed that the MRI rupture signs for these highly cohesive gel implants were the same as those for standard gel implants. Although that single-center study demonstrated a low rupture rate and high patient satisfaction with the Style 410 implant, the study needed to be validated further across multiple sites to confirm the accuracy of the results. The current study is similar in design to the Hedén trial but expands the subject cohort to include seven sites across Europe.

\section{Subjects and Methods}

\section{Study Design}

The multicenter study was conducted in six European countries (Sweden, Switzerland, Belgium, Denmark, Finland, and The Netherlands [2 sites]) to investigate the safety and effectiveness of Style 410 implants 5 to 11 years after implantation. A total of 163 subjects $(\sim 70 \%$ had augmentation [ $n=112$ ], $15 \%$ had reconstruction $[n=25]$, and $15 \%$ had revision $[n=26]$ ) underwent a physical examination followed by a breast MRI between August 2005 and December 2007.

The seven investigational sites were selected on the basis of professional training and experience in aesthetic and reconstructive surgery, prior experience conducting clinical studies, and history of implanting the devices being studied. Informed consent was obtained from all the subjects, and ethics committees provided oversight.

The data collected at the physical examination included certain local complications; the subjects' histories of lactation, reproduction, and breast disease; and the investigator's assessment of rupture status. The subjects completed a quality-of-life questionnaire to assess changes in their lives due to the breast implantation surgery.

All MRIs were performed "closed" with the use of a bilateral dedicated breast coil with unilateral and bilateral switch positions. The local MRI facility was blinded to the Investigator's clinical judgment of whether the implants were ruptured. The MRI facility forwarded the MRI images on films or disk to the Investigator, who in turn forwarded the images to the MRI Central Reviewer in the United States, a radiologist with extensive experience interpreting MRIs of Style 410 implants.

The Central Reviewer examined all the images to determine rupture. One of four possible outcomes was assigned to each image: 1 (no evidence of rupture), 2 (evidence of rupture), 3 (indeterminate outcome), and 4 (unreadable image). A rupture diagnosis was made when clear evidence on the images showed the linguini sign, subcapsular line, or inverted loop. The absence of these signs resulted in a diagnosis of no rupture. An indeterminate finding signified an image suggestive of rupture but not definitive.

\section{Subjects}

The subjects were required to be women who had undergone implantation with an Allergan Style 410 shaped gel breast implant between the years 1995 and 2001 and retained at least one original implant. The subjects also had to be willing and eligible to undergo an MRI scan (e.g., no implanted metal or metal devices, no current pregnancy or breastfeeding, and no history of severe claustrophobia).

Based on the indication for implantation, the subjects were classified into one of three cohorts as follows: augmentation (subject dissatisfaction with breast size or shape, asymmetry, ptosis, or aplasia), reconstruction (mastectomy for cancer or trauma, prophylactic mastectomy, or contralateral asymmetry of the nonreconstructed breast), or revision (previous augmentation or reconstruction with silicone- or saline-filled breast implants).

\section{Devices}

The Style 410 implants have an anatomic shape similar to the natural breast shape compared with the round shape of standard implants. They are filled with a highly cohesive gel to create a form-stable device that provides a long-lasting result in vivo [1]. Biocell texturing on the implant shell promotes tissue adherence to reduce implant rotation and capsular contracture [2]. Style 410 implants are available in a wide range of shapes (a matrix involving 12 combinations of implant height and projection ratios that extend across a range of base widths), enabling the physician to select an implant appropriate to each patient's needs.

\section{Statistical Analyses}

All eligible subjects and implants were pooled to form one cohort for analysis. The primary end point was the prevalence of rupture according to MRI results. Secondary analyses of MRI rupture findings were stratified by years of implantation, with implant age rounded to the nearest year. Implant age (time elapsed in vivo) was calculated as the time from the date of implantation until the date of a subject's MRI procedure.

Descriptive statistics tabulated the frequency of local complications after implantation, pre- and postimplantation 
lactation and reproduction problems, and the occurrence of breast disease. Quality-of-life questions concerning general and specific changes in subjects' lives due to breast implantation surgery were rated on a 7-point scale and then categorized with the responses of "much," "quite," and "a bit" grouped together to show the percentage of subjects improved, unchanged, or worsened after implantation.

\section{Results}

\section{Subject and Surgical Characteristics}

The demographic data showed that most of the subjects were white and married (Table 1), with a median age of 43 years (range, 25-83 years). The majority of the 163 subjects received implants for cosmetic augmentation $(n=112)$, although reconstruction $(n=25)$ and revision $(n=26)$ subjects also were represented. Most of the subjects underwent MRI screening on the same day as the physical exam, with a median time of 0 days (range, 0-63 days) elapsed between exam and MRI.

Table 1 Demographic characteristics $(n=163$ subjects)

\begin{tabular}{|c|c|c|}
\hline Characteristic & $n$ & $\%$ \\
\hline \multicolumn{3}{|l|}{ Age at implantation (years) } \\
\hline $18-19$ & 0 & 0 \\
\hline $20-29$ & 10 & 6.1 \\
\hline $30-39$ & 43 & 26.4 \\
\hline $40-49$ & 58 & 35.6 \\
\hline $50-59$ & 32 & 19.6 \\
\hline $60-69$ & 18 & 11.0 \\
\hline $70+$ & 2 & 1.2 \\
\hline \multicolumn{3}{|l|}{ Race } \\
\hline Caucasian & 160 & 98.2 \\
\hline Black/African & 1 & 0.6 \\
\hline Asian & 1 & 0.6 \\
\hline Hispanic & 0 & 0 \\
\hline Other & 1 & 0.6 \\
\hline \multicolumn{3}{|l|}{ Marital status } \\
\hline Single & 36 & 22.1 \\
\hline Married & 96 & 58.9 \\
\hline Widowed & 9 & 5.5 \\
\hline Separated & 7 & 4.3 \\
\hline Divorced & 14 & 8.6 \\
\hline No answer & 1 & 0.6 \\
\hline \multicolumn{3}{|l|}{ Education } \\
\hline Primary/secondary school & 22 & 13.5 \\
\hline High school & 89 & 54.6 \\
\hline College & 52 & 31.9 \\
\hline
\end{tabular}

Table 2 Surgical and device characteristics ( $n=300$ implants $)$

\begin{tabular}{lrr}
\hline Characteristic & $n$ & $\%$ \\
\hline Implant placement & & \\
$\quad$ Subglandular & 177 & 59.0 \\
Submuscular & 121 & 40.3 \\
$\quad$ Unknown & 2 & 0.7 \\
Incision site & & \\
Periareolar & 22 & 7.3 \\
Inframammary & 242 & 80.7 \\
Mastectomy scar & 29 & 9.7 \\
Axillary & 2 & 0.7 \\
Breast scar & 3 & 1.0 \\
Other & 4 & 1.3 \\
Product style & & \\
Full height/full projection (FF) & 5 & 1.7 \\
Full height/moderate projection (FM) & 132 & 44.0 \\
Moderate height/moderate projection (MM) & 54 & 18.0 \\
Low height/full projection (LF) & 1 & 0.3 \\
Unknown & 108 & 36.0 \\
Implant age at MRI scan (years) & & \\
5 & 13 & 4.3 \\
6 & 52 & 17.3 \\
7 & 58 & 19.3 \\
8 & 47 & 15.7 \\
6 & 60 & 20.0 \\
10 & 16.7 \\
11 & 60 & 6.7 \\
\hline & & \\
& &
\end{tabular}

The majority of the 300 devices were placed in a subglandular position using an inframammary incision site (Table 2). The most commonly used implant was fullheight moderate projection. The most popular of these implants was the $270 \mathrm{-g}$ size. The median implant age at MRI was 8 years (range, 5-11 years).

\section{Safety}

The vast majority of implants evaluated by MRI showed no evidence of rupture 5 to 11 years after implantation (Table 3). According to the MRI results, five implants showed evidence of rupture, yielding a rupture prevalence of $1.7 \%$ at a median implant age of 8 years. There were no indeterminate results, but two scans were unreadable. The five implants classified as ruptured showed an inverted loop on the MRI. Three of the five implants also had subcapsular lines.

The length of implantation at the time of rupture diagnosis was 6 years for one implant, 7 years for one implant, and 8 years for three implants. No ruptures were identified 9 to 11 years after implantation. 
Table 3 Rupture summary ( $n=300$ implants)

\begin{tabular}{lrl}
\hline Characteristic & $n$ & $\%$ \\
\hline MRI finding & 293 & \\
$\quad$ No evidence of rupture & 5 & 97.7 \\
Evidence of rupture & 0 & 1.7 \\
Indeterminate & 2 & 0 \\
Unreadable & & 0.7 \\
Prevalence of rupture (years) & 0 & \\
5 & 1 & 0 \\
6 & 1 & 2.4 \\
7 & 3 & 1.3 \\
8 & 0 & 6.3 \\
9 & 0 & 0 \\
10 & 0 & 0 \\
11 & & \\
\hline
\end{tabular}

Of the 300 implants assessed by physical examination at baseline, 298 were not suspected of rupture, and two had no answer. Of the 298 implants not suspected of rupture at baseline, 5 received a diagnosis of rupture by MRI. Thus, all the ruptures were silent and not confirmed by explantation.

Capsular contracture was detected for $5.3 \%$ of the implants. All were grade 3, and there were no cases of grade 4 capsular contracture. Asymmetry occurred for $7 \%$ of the implants. The vast majority of implants (95\%) had no visible creases (wrinkling).

Of the 94 women who attempted breastfeeding before implantation, $36.2 \%$ experienced lactation problems. After implantation, 27 women reported attempts to breastfeed, and $22.2 \%$ of those experienced a problem. Both before and after implantation, the most common lactation problem was inadequate milk production. Regarding reproduction, $25.8 \%$ reported experiencing reproductive problems before receiving their implants, and $8.6 \%$ reported problems after implantation. Miscarriage was the most common reproductive problem both before and after implantation, and more than one-third of the women with a postimplantation reproductive problem (35.7\%) also had a preimplantation problem. Breast carcinoma was reported for $16 \%$ of the subjects before implantation and for $1.8 \%$ after implantation.

\section{Effectiveness}

Several general quality-of-life measurements showed little change after implantation (Table 4). Physical health, ability to remain active, and working capacity were marked as unchanged by most of the subjects. One general category that did show improvement was overall sense of wellbeing, which $63 \%$ of subjects found to be better.
Table 4 Subject quality of life

\begin{tabular}{lllc}
\hline Characteristic & $\begin{array}{l}\text { Better } \\
(\%)^{\mathrm{a}}\end{array}$ & $\begin{array}{l}\text { Unchanged } \\
(\%)\end{array}$ & $\begin{array}{l}\text { Worse } \\
(\%)^{\mathrm{b}}\end{array}$ \\
\hline General changes & 16 & 78 & 6 \\
$\quad$ Physical health & 63 & 33 & 5 \\
Sense of well-being & 38 & 59 & 2 \\
Contact with other people & 43 & 55 & 3 \\
Partner/family life & 18 & 76 & 6 \\
Remain active & 9 & 86 & 6 \\
Working capacity & 56 & 40 & 4 \\
Whole Life & & & \\
Specific Changes & 77 & 18 & 6 \\
Body perception & 69 & 28 & 4 \\
Self-esteem & 15 & 75 & 10 \\
Ability to exercise & 72 & 21 & 8 \\
Wearing clothes & 65 & 31 & 4 \\
Personal charisma & 61 & 34 & 4 \\
Attraction ability & 45 & 46 & 10 \\
Intimate experiences & 64 & 28 & 9 \\
Clothes shopping & & & \\
\hline
\end{tabular}

a Includes responses of "much better," "quite better," and "a bit better"

b Includes responses of "much worse," "quite worse," and "a bit worse"

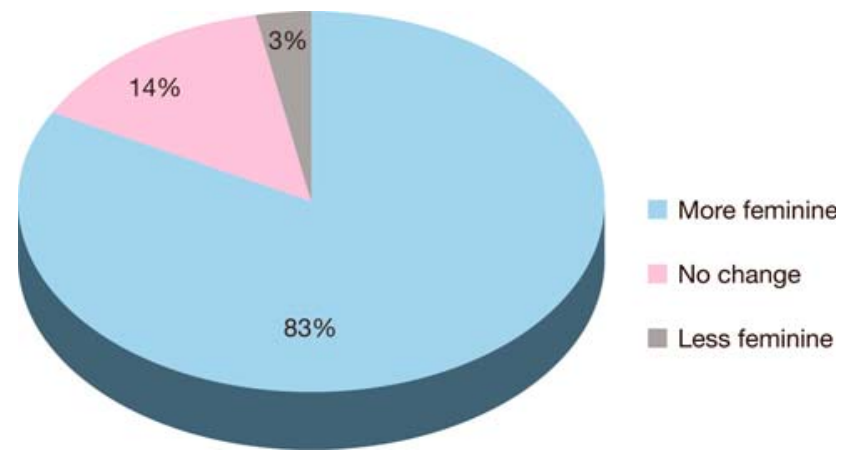

Fig. 1 Quality-of-life subject ratings on femininity

In contrast, most of the specific measurements showed striking improvement after implantation. Body perception, self-esteem, feeling of wearing clothes, personal charisma, and attraction ability were ranked as better by the majority of women. Clothes shopping was easier for most women, and a large proportion stated that they felt more feminine (Fig. 1). Notably, 91\% of the subjects reported that their breast implantation surgery overall was advantageous (Fig. 2). The subject photographs in Fig. 3 provide evidence of the natural aesthetic outcome achieved with Style 410 implantation and how well the results hold up over time. 


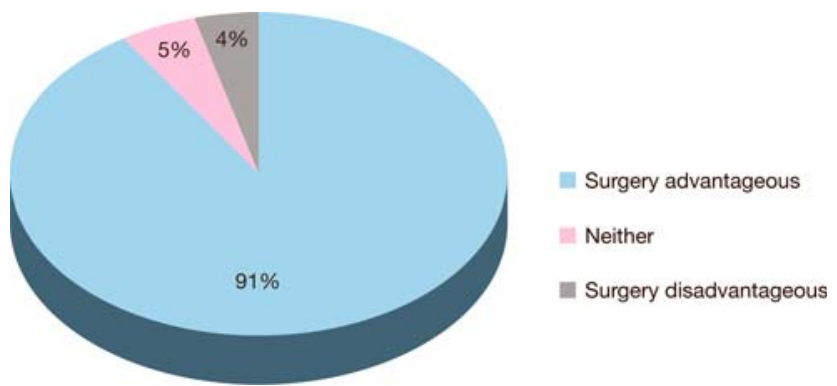

Fig. 2 Quality-of-life subject satisfaction

\section{Discussion}

Our study corroborated on a larger scale the results of the Hedén single-center study because it was performed across multiple European sites and also obtained longer-term data after implantation. Whereas Hedén et al. [1] found a rupture rate of 0.3 to $1.0 \%$ at a median implantation time of 6 years in a Swedish cohort of 144 women, our study found a rupture rate of $1.7 \%$ at a median implantation time of 8 years. This certainly is consistent with the earlier findings and demonstrates the long-term durability of the Style 410 implant.

An interesting finding in both studies was that no implants were suspected of rupture at physical examination. This finding is consistent with the published literature [3], which demonstrates that physical examination is not a reliable way to diagnose ruptures, and that it may be exacerbated by the more cohesive nature of the gel in the Style 410 implant, resulting in greater difficulty detecting physical signs of rupture. Notably, the MRI rupture signs
Fig. 3 Side and frontal views. a View before implantation. b View 6 months after augmentation with a 395-g Style 410 full-height moderate projection implant. c View 10 years after implantation
(A)
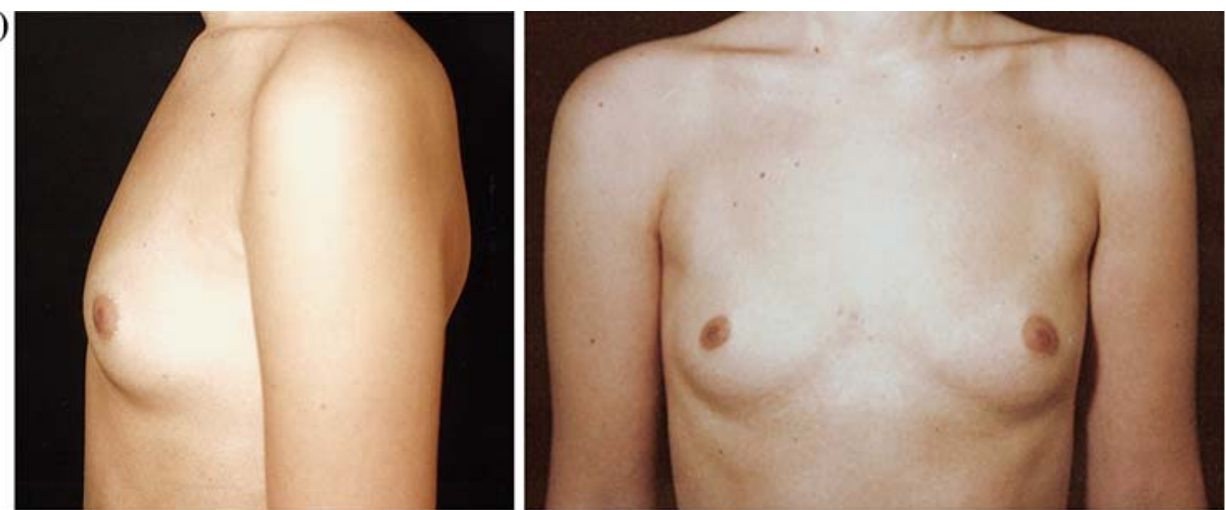

(B)
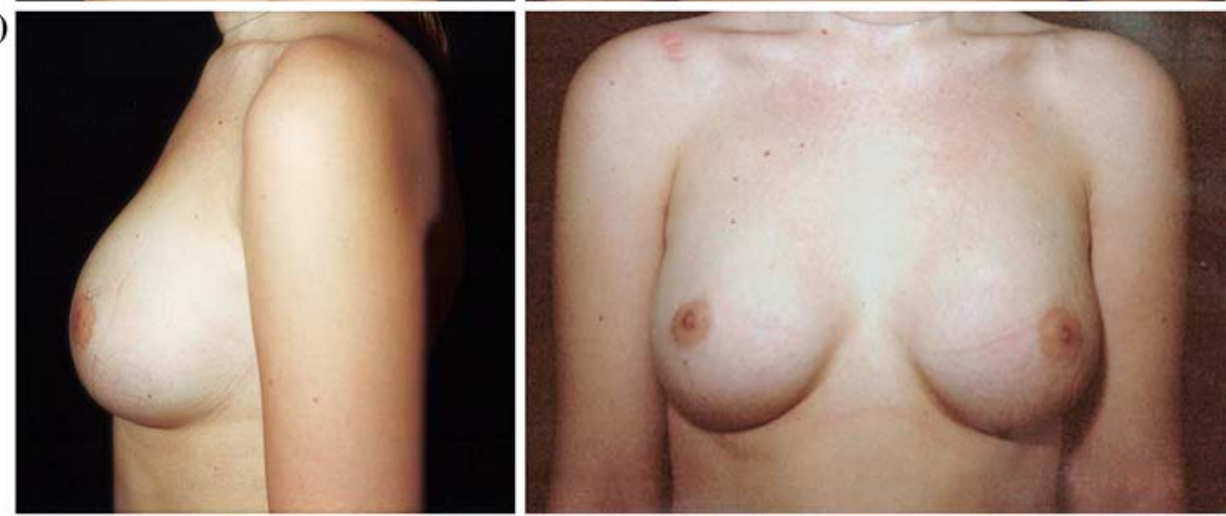

(C)

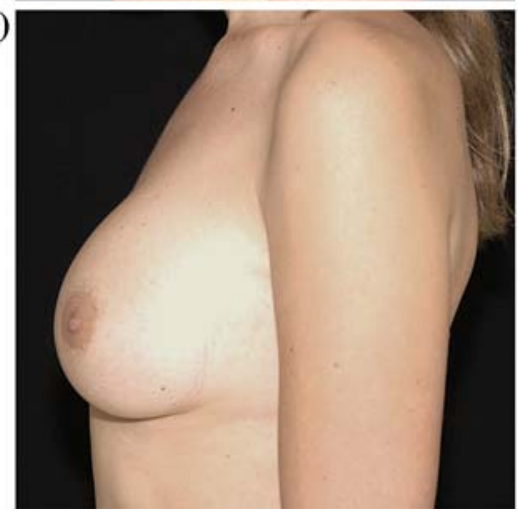


(e.g., inverted loop, subcapsular line) found in both studies were the same for these highly cohesive implants as those seen on MRIs of ruptured implants with less cohesive silicone gel [4].

Although our study and the earlier Hedén study used the gold standard rupture detection method of MRI, the rupture rates were based on the rupture prevalence at a point in time after implantation, approximately 8 years after implantation in our study. A more accurate depiction of rupture rates is obtained through serial MRIs of the same subjects over time. This method was used in the U.S. pivotal study of the Style 410 shaped gel implants, which found a rupture incidence rate of $0.8 \%$ through 3 years after implantation based on MRI screening at years 1 and 3 [5]. This study included 941 augmentation, reconstruction, and revision subjects, approximately one-third of whom participated in the serial MRI component of the study. A third MRI at year 5 for these subjects yielded an implant rupture incidence rate of $3.2 \%$ through 5 years [6], slightly higher than that found in our study, but still low.

The $5.3 \%$ capsular contracture rate found in our study is consistent with the $5.6 \%$ rate found in the study of Hedén et al. [1]. Other researchers also have found little or no capsular contracture using this textured, highly cohesive device. Brown's series of 150 augmentation and reconstruction patients implanted in Canada with the Style 410 implant had no cases of Baker 3 or 4 capsular contracture during a follow-up period up to 3 years [7]. Similarly, 263 augmentation patients in Brazil also had no Baker 3 or 4 contractures [8]. A prospective study in Spain found no capsular contracture in 45 patients during a 1-year followup period [9], and for 25 patients in Switzerland followed 4 to 5 years, no Baker 3 or 4 capsular contracture was found [10]. The prospective U.S. pivotal study reported a 5-year capsular contracture risk rate of $3.3 \%$ for augmentation subjects and $9.6 \%$ for reconstruction subjects [6]. The low rate of capsular contracture seen with the Style 410 implant across these multiple studies is likely attributable to both the Biocell textured implant surface and the highly cohesive nature of the gel, which applies pressure to the inside of a tight capsule [5, 7].

Our study also demonstrated the low rate of wrinkling for the Style 410 devices, with only $5 \%$ of the implants having any visible wrinkles. Long the bane of physicians seeking natural results in the days of saline implants, wrinkles are an uncommon occurrence with the highly cohesive Style 410 implant [7]. This is also borne out in the U.S. pivotal study, which found a wrinkling rate lower than $1 \%$ for augmentation subjects and $2.5 \%$ for reconstruction subjects through 5 years [6]. The form-stable nature of the Style 410 allows it to maintain its shape and upper pole fill while resisting collapse and folding, thus minimizing the opportunity for wrinkling [7].
As in the study of Hedén et al. [1], quality-of-life measurements showed postimplantation improvements in factors such as body perception, self-esteem, and femininity as well as high rates of subject satisfaction. Whereas other studies have shown satisfaction and psychosocial improvement in the short term after cosmetic augmentation $[5,11,12]$. our study presents these findings from a vantage point of 8 years, on the average, after implantation, pointing to the prolonged stability of the results.

\section{Conclusion}

The Style 410 anatomically shaped form-stable gel breast implants have demonstrated long-term safety and effectiveness. Up to 11 years after implantation, the vast majority of subjects were satisfied with their implants, and the complication rates, including rupture, remained low.

Acknowledgments The authors thank Peter Emanuelsson, M.D., and Lilan Engel, M.D., for serving as coinvestigators in the study and Allergan for financial support. Drs. Hedén, Bronz, Elberg, Deraemaecker, Brenner, Svarvar, van Tetering, and van der Weij received research support from Allergan for conducting this study. Ms. Murphy and Ms. Slicton are Allergan employees and stockholders.

Open Access This article is distributed under the terms of the Creative Commons Attribution Noncommercial License which permits any noncommercial use, distribution, and reproduction in any medium, provided the original author(s) and source are credited.

\section{References}

1. Hedén P, Boné B, Murphy DK, Slicton A, Walker PS (2006) Style 410 cohesive silicone breast implants: safety and effectiveness at 5 to 9 years after implantation. Plast Reconstr Surg 118:1281-1287

2. Danino AM, Basmacioglu P, Saito S, Rocher F, Blanchet-Bardon C, Revol M, Servant J (2001) Comparison of the capsular response to the Biocell RTV and Mentor 1600 Siltex breast implant surface texturing: a scanning electron microscopic study. Plast Reconstr Surg 108:2047-2052

3. Hölmich LR, Fryzek JP, Kjøller K, Breiting VB, Jørgensen A, Krag C, McLaughlin JK (2005) The diagnosis of silicone breastimplant rupture: clinical findings compared with findings at magnetic resonance imaging. Ann Plast Surg 54:583-589

4. Herborn CU, Marincek B, Erfmann D, Meuli-Simmen C, Wedler V, Bode-Lesniewska B, Kubik-Huch RA (2002) Breast augmentation and reconstructive surgery: MR imaging of implant rupture and malignancy. Eur Radiol 12:2198-2206

5. Bengtson BP, Van Natta BW, Murphy DK, Slicton A, Maxwell GP (2007) Style 410 highly cohesive silicone breast implant core study results at 3 years. Plast Reconstr Surg 120(Suppl 1): $40 \mathrm{~S}-48 \mathrm{~S}$

6. (2008) Natrelle silicone-filled breast implants (package insert, Canada). Allergan Inc., Santa Barbara, CA

7. Brown MH, Shenker R, Silver SA (2005) Cohesive silicone gel breast implants in aesthetic and reconstructive breast surgery. Plast Reconstr Surg 116:768-779 
8. Graf RM, Bernardes A, Rippel R, Araujo LR, Damasio RC, Auersvald A (2003) Subfascial breast implant: a new procedure. Plast Reconstr Surg 111:904-908

9. Serra-Renom J, Garrido MF, Yoon T (2005) Augmentation mammaplasty with anatomic soft, cohesive silicone implant using the transaxillary approach at a subfascial level with endoscopic assistance. Plast Reconstr Surg 116:640-645

10. Bronz G (2002) A comparison of naturally shaped and round implants. Aesthet Surg J 22:238-246
11. Cash TF, Duel LA, Perkins LL (2002) Women's psychosocial outcomes of breast augmentation with silicone gel-filled implants: a 2-year prospective study. Plast Reconstr Surg 109: 2112-2121

12. Banbury J, Yetman R, Lucas A et al (2004) Prospective analysis of the outcome of subpectoral breast augmentation: sensory changes, muscle function, and body image. Plast Reconstr Surg 113:701-707 